\title{
Perceived slant as a function of direction of regard'
}

Four groups of Ss viewed trapezoid shaped transparencies in a tachistoscopic device. Each group estimated that slant of the stimulus when it was photographed. Two groups looked up at the transparencies, two down. The results indicated that direction of regard alone was insufficient to influence the perceived slant. As in previous studies, relative midpoint height of the vertical edges of the trapezoid was a depth cue as was end ratio. The results were considered in terms of muscle involvement and shape invariance hypothesis.

If a rectangle is rotated about its vertical axis, its two dimensional projection will be a trapezoid with one vertical end shorter than the other. If the rectangle is viewed from above, the midpoint of the shorter end will be higher in the picture plane than the midpoint of the longer end. If viewed from the bottom, the opposite is true (Dunn, Grey, \& Thompson, 1965). This relative difference in midpoint height was called RMH by Dunn \& Thomas (1965). It was defined as "the height of the shorter-end midpoint minus the height of the longerend midpoint." They found that if Ss looked straight ahead at photographs of trapezoids, those with a highpositive RMH value were generally seen as more slanted than those with a low-positive or negative $\mathbf{R M H}$ value.

From the results above, it would appear that the Ss responded as if the rectangles were below them. The question of how they would respond if they were to look up at the same stimuli then arises. If the Ss perceived the rectangles as above them, their experience with stimuli so positioned might be expected to reverse the effect described above. Looking down, on the other hand, might be expected to enhance the effect found earlier since the viewing position depicted by the camera and the kinesthetic cues could be in better agreement for the high-positive RMH cues. Such an explanation seens to be a logical deduction from the sensory-tonic theory of perception (Werner \& Wapner, 1952).

Subjects

The Ss were 64 psychology students at the University of Minnesota, Morris.

\section{Apparafus}

The apparatus consisted of eight trapezoidal transparencies, one rectangular transparency, and a tachistoscopic device, all of which have been described in detail elsewhere (Dunn \& Thomas, 1965). Four of the transparencies had end ratios of 15:16 and four of 13:16. In each group of four, two had absolute RMH differences of $24.5^{\prime}$ of arc (visual angle) and two had differences of $44.1^{\prime}$ of arc. Each transparency could be placed in the tachistoscope so as to have either a positive or negative RMH value. Each could be placed in the apparatus with its shorter edge to the left or right of the observer. All stimuli were of the same length, and the height of the longer edge was the same for all stimuli. The rectangle was also of the same length $\left(4^{\circ} 46^{\prime}\right.$ of arc) and was of the same height as the longer end of the trapezoids ( $2^{\circ} 23^{\prime}$ of arc).

The response of the $S$ was measured by the pivoting of a rod around a right-end vertical axis. $S$ moved it to a slant which appeared equivalent to the slant of the stimulus presented to him (see Dunn \& Thomas, 1965).

The tachistoscope could be sloped at any one of the four angles, forcing $S$ to look either up or down at the stimulus. The angles were: $-2 \theta-1 / 2^{\circ}(\mathrm{D}-) ;-10-2 / 3^{\circ}$ (D); $10-2 / 3^{\circ}(U) ; 20-1 / 2^{\circ}\left(U_{+}\right)$.

\section{Procedure}

A 4 by 4 by 2 by 2 Latin square design was used. Sixteen Ss were run in each of the four directions of view. Each $S$ was presented with all 16 combinations of the four RMH values $\left(-44.1^{\prime},-24.5^{\prime}, 24.5^{\prime}, 44.1^{\prime}\right)$, the two end-ratio conditions, and the two left right positions of the long end of the trapezold. These were presented in the same Latin square to each group (D-, D, U, \& D+).

Stimulus presentations were made in the following: manner: 10-sec. presentation of the trapezoid, 30-sec. response and rest period, repeat cycle. All stimuli were responded to including the rectangle.

The Ss were instructed to respond to the way the stimuli appeared rather than to their calculated estimate of the slant by use of the rod. If the $S$ felt that there was a discrepancy between the way the stimulus appeared and the way he thought it was actually oriented, he was permitted to make a second response, which did not count. Initial instructions were given by showing S a swinging door opened both ways and indicating to him how slanted it was by use of the rod.

Results

An analysis of variance was performed. Since the $\mathrm{F}$-score for sequences and square uniqueness were less than one, the author did not use Box's (1953) correction as Dunn \& Thompson (1965) did when using a single Latin Square. As suggested by Grant (1948), the residual and square uniqueness components were combined to form a single error term for all within Ss effects having 840 degrees of freedom. Between Ss effects were tested by the significant ( $F=4.83$ with 45 degrees of freedom; $p<.01$ ) Ss/sequences.

Directions by trials was the only significant effect involving direction of view $(F=1.60$ with 45 degrees of 
Table 1. Mean Perceived Slant in Degrees

\begin{tabular}{|c|c|c|c|c|c|c|c|c|c|c|c|c|c|c|c|}
\hline Direction of View & & D- & & & $D$ & & & $\mathrm{U}$ & & & $\mathrm{U}_{+}$ & & Row & Avera & ges \\
\hline Ratio & $15: 16$ & $13: 16$ & Av. & $15: 16$ & $13: 16$ & Av. & $15: 16$ & 13:16 & Av. & $15: 16$ & 13: 16 & Av. & $15: 16$ & $13: 16$ & Av. \\
\hline $44 . \gamma^{\prime}$ & 16.7 & 22.0 & 19.3 & 16.0 & 16.9 & 16.4 & 6.3 & 15.6 & 11.0 & 17.1 & 21.5 & 19.3 & 14.0 & 19.0 & 16.5 \\
\hline 24.$]^{\prime}$ & 16.3 & 17.9 & 17.1 & 10.3 & 15.0 & 12.7 & 8.3 & 18.1 & 13.3 & 13.2 & 21.0 & 17.1 & 12.0 & 18.0 & 15.0 \\
\hline$-24.5^{\prime}$ & 7.4 & 9.0 & 8.2 & 5.9 & 12.2 & 9.1 & 3.8 & 6.8 & 5.3 & 8.6 & 19.2 & 13.9 & 6.4 & 11.8 & 9.1 \\
\hline$-44.1^{\prime}$ & 1.0 & 11.9 & 6.5 & 5.9 & 12.2 & 9.1 & 3.3 & 8.1 & 5.7 & 7.9 & 18.5 & 13.3 & 4.5 & 12.7 & 8.6 \\
\hline Column Averoge & 10.4 & 15.2 & 12.8 & 9.5 & 14.1 & 11.8 & 5.4 & 12.2 & 8.7 & 11.7 & 20.0 & 15.9 & 9.2 & 15.4 & 12.3 \\
\hline
\end{tabular}

freedom; $p<.01$ ). Both the direction main effect and its interaction with treatments did not reach significance. The component of variance which contributed to the significant interaction was the linear $x$ linear interaction. The F-score with one degree of freedom was $17.20(p<.01)$. However, the only slope that was itself significantly greater than zero was the slope for the D- group. An F-score (one degree of freedom) of 13.38 was obtained $\left(p<1-.95^{1 / 4}\right)$. The reduction in score seems to be slightly greater with negative $\mathrm{RMH}$ values, but this cannot be clearly shown, statistically. In general, as Table 1 shows, the negative RMH values were seen as less slanted than the positive values. That the difference was significant ( $F=14.21$ with 3 degrees of freedom; $p<.01$ ) post-anova test, the studentized range statistic, indicated that the responses to the positive RMH values were significantly different $(p<.05)$ from the negative values, but some signed RMH levels were not significantly different from each other. This same result was found when the two different endratios were analyzed separately.

A significant effect of direction of orientation of the trapezoid was found ( $F=4.91$ with one degree of freedom; $p<.05)$. When the short end was to S's left, his average slant was $13.4^{\circ}$ and when to this right, $10.9^{\circ}$.

Discussion

The results support two earlier studies (Dunn, 1965; Dunn \& Thomas, 1965), but do not support the hypothesis that upward viewing reverses the RMH effect found in these studies. Certainly the data does not strongly suggest that the muscle involvement of looking up will reverse the RMH effect. Dunn, Grey, \& Thompson(1965) have discussed possible responses of an $\mathrm{S}$ to stimuli above him, but on a plane extending below his eye level. The responses, they showed, would be predicted to be similar to those given when $\mathrm{S}$ was actually looking down at the stimulus from above. If in the absence of a plane, $S$ judged the object with respect to an imaginary place extending below his eye level, the results of this study are easily explained.

Little need be said about the significant effect of different end-ratios $(F=36.24$ with one degree of freedom; $p<.01$ ). Such findings are typical of most trapezoidal studies of slant.

The effect of orientation of stimuli has been found before (Nixon, 1965), however, subsequent aiterations in the apparatus changed the direction indicating that such a result may be easily produced by asymmetries in the apparatus. On the other hand, the findings of Gaffron (1962) which showed that the left side of a picture seems to have more depth than the right for righteye dominant people might indicate that such a result may have been more than an apparatus artifact.

The findings of this study and the earlier studies (Dunn, 1965; Dunn \& Thomas, 1965) have distinctimplications for the invariance hypothesis. Unless $\mathrm{S}$ viewed each stimulus object of a different RMH value as having a different shape unslanted, he would be indicating several different degrees of perceived slant for a similarly shaped figure with equal end-ratios. That the Ss actually did this is indicated by the similarity of these results to those of Dunn \& Thomas (1965) where the Ss were instructed that they were looking at slanted rectangles.

\section{References}

Box, G. E. P. Non-normality and tests on variance. Biometrika, $1953,40,318-335$.

Dunn, B. E. Perceived slant as a function of relative height. Percept. mot. Skills, 1965, 20, 708.

Dunn, B. E., Grey, G. C., \& Thompson, D. Relative height on the picture-plane and depth perception. Percept. mot. Skills, 1965 , $21,227-236$.

Dunn, B. E., \& Thomas, S. W. Relative height and relative size as monocular depth dues in the trapezoid. Percept. mot. Skills. 1966, 22, 275-281.

Grant, D. A. The latin square principle in the design and analysis of psychological experiments. Psychol. Bull., 1948, 45, 427-442.

Nixon, M. C. Personal communication. 1965.

Werner, H., \& Wapner, S. Towards a general theory of perception. Psychol. Rev., 1952, 59, 324-338.

Zener, K., \& Gaffron, M. Perceptual experience: An analysis of its relations to the external world through internal processing. In S. Koch (Ed.), Psychology: A study of a science. Vol. 4., New York: McGraw-Hill, 1962. Pp. 515-618.

\section{Note}

1. This work was supported in part by National Science Foundation Grant B1781. 